\title{
Popliteal Artery Injury Following Traumatic Knee Dislocation - Case Report
}

\author{
Filipe Sa Malheiro*, André Santos, Sergio Pita, José Martel, José Brenha
}

Centro Hospitalar do Baixo Vouga - Aveiro

*Corresponding author: Filipe Sa Malheiro, Centro Hospitalar do Baixo Vouga - Aveiro. Received date: October 14, 2021; Accepted date: October 25, 2021; Published date: October 29,2021

Citation: Filipe Sa Malheiro, André Santos, Sergio Pita, José Martel, José Brenha. (2021) Popliteal Artery Injury Following Traumatic Knee Dislocation - Case Report. J. Clinical Orthopedics and Trauma Care, 3(1); DOI:10.31579/2694-0248/014

Copyright: (C) 2021 Filipe Sa Malheiro, This is an open access article distributed under the Creative Commons Attribution License, which permits unrestricted use, distribution, and reproduction in any medium, provided the original work is properly cited.

\begin{abstract}
Knee dislocation is a devastating injury that can compromise the limb's viability. This trauma is associated with muscular and ligamentar extensive lesions. Obese patients can suffer of knee dislocation resultant from falls at the same level, and these "super-low" energy dislocations are associated with a surprising rate of neurovascular complications. The popliteal artery may be involved in up to $60 \%$ of cases, and the prognosis is considerably worse. In these cases an emergent approach is mandatory. Delayed diagnosis and treatment can result in up to $80 \%$ of amputations of the extremity.

The authors present a patient that was admitted at the Emergency Room with knee pain and deformity after a fall at the same high. After the diagnose and reduction of the anterior dislocation, an echo-doppler and CT angiography were performed, and revealed a lesion in popliteal artery. After immobilized with a long leg plaster cast, the patient was transferred to a hospital with Vascular Surgery Department, and underwent revascularization of the limb. Despite the severity of the vascular injury the patient had a very good outcome.

Key words: popliteal artery injury; immobilization; rehabilition
\end{abstract}

\section{Introduction}

Knee dislocation is a relatively rare injury. The extensive lesion of soft tissues and the high incidence of neurological and mainly vascular complications, associated to this event, can compromise the limb's viability. $[1,2]$ Knee dislocations are usually related to high-energy trauma, being associated with multiple injuries, namely ligaments, meniscal, neurovascular and fractures. However, in obese patients, they can result from falls at the same level, and these "super-low" energy dislocations are associated with a surprising rate of neurovascular complications. [3, 4] The popliteal artery may be involved in up to $60 \%$ of cases. It is especially vulnerable in this type of injury, as it is fixed either superiorly in the adductor hiatus or inferiorly in the soleus annulus. $[2,5,6]$ In case of popliteal artery injury, the prognosis is considerably worse and an emergent approach is mandatory. Delayed diagnosis and treatment can result in up to $80 \%$ of amputations of the extremity. [7, 8] Opinions differ on whether conservative treatment is sufficient or surgical repair is necessary to achieve a stable knee. $[9,10]$

\section{Clinical Case}

A 59-year-old female patient was admitted at the Emergency Room after a fall at the same high on the sidewalk. As relevant comorbities, she had BMI $=43 \mathrm{~kg} / \mathrm{m}^{2}$, dyslipidemia and hypertension. On objective examination, she had left knee deformity, with pain on mobilization. She had no neurological deficits in the lower or upper limbs. Distal pulses were palpable but diminished on the affected side.The radiographs (Figure 1) confirmed the anterior dislocation of the knee with no associated fractures. She was immediately submitted to closed reduction of the dislocation under sedation and immobilized with a posterior long leg splint.

After reduction, distal pulses remained diminished and then echo-doppler was performed, which revealed triphasic flow in the common and superficial femoral arteries on both sides, presenting inferior velocities at the left side and, distally, an evident asymmetry of the flow. Subsequently, a CT angiography was required which revealed a zone of flow interruption in the left popliteal artery, measuring about 7-8mm. However, flow was observed distally to this level, with a smaller caliber than the contralateral side (Figure 2). 


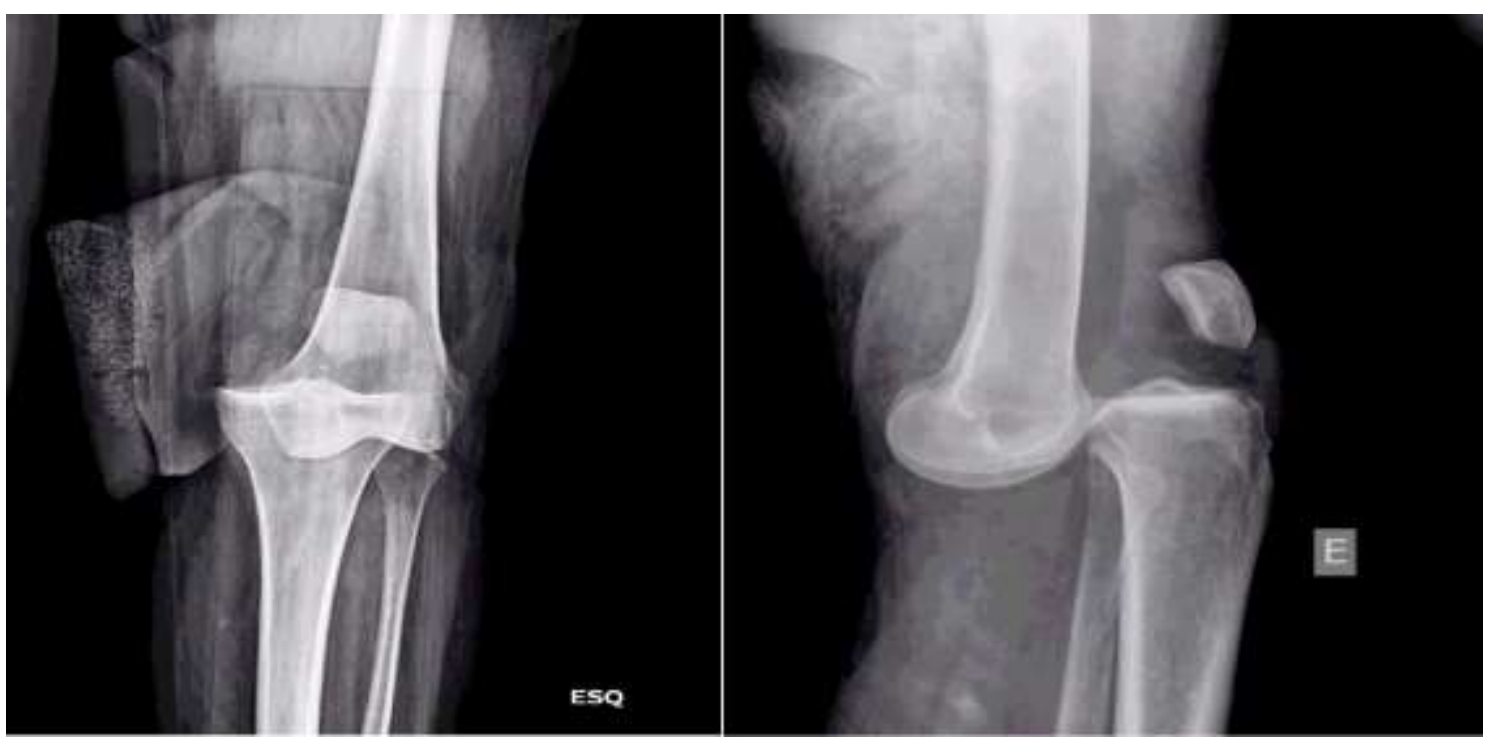

Figure 1: X-Ray of the knee before reduction and immobilization
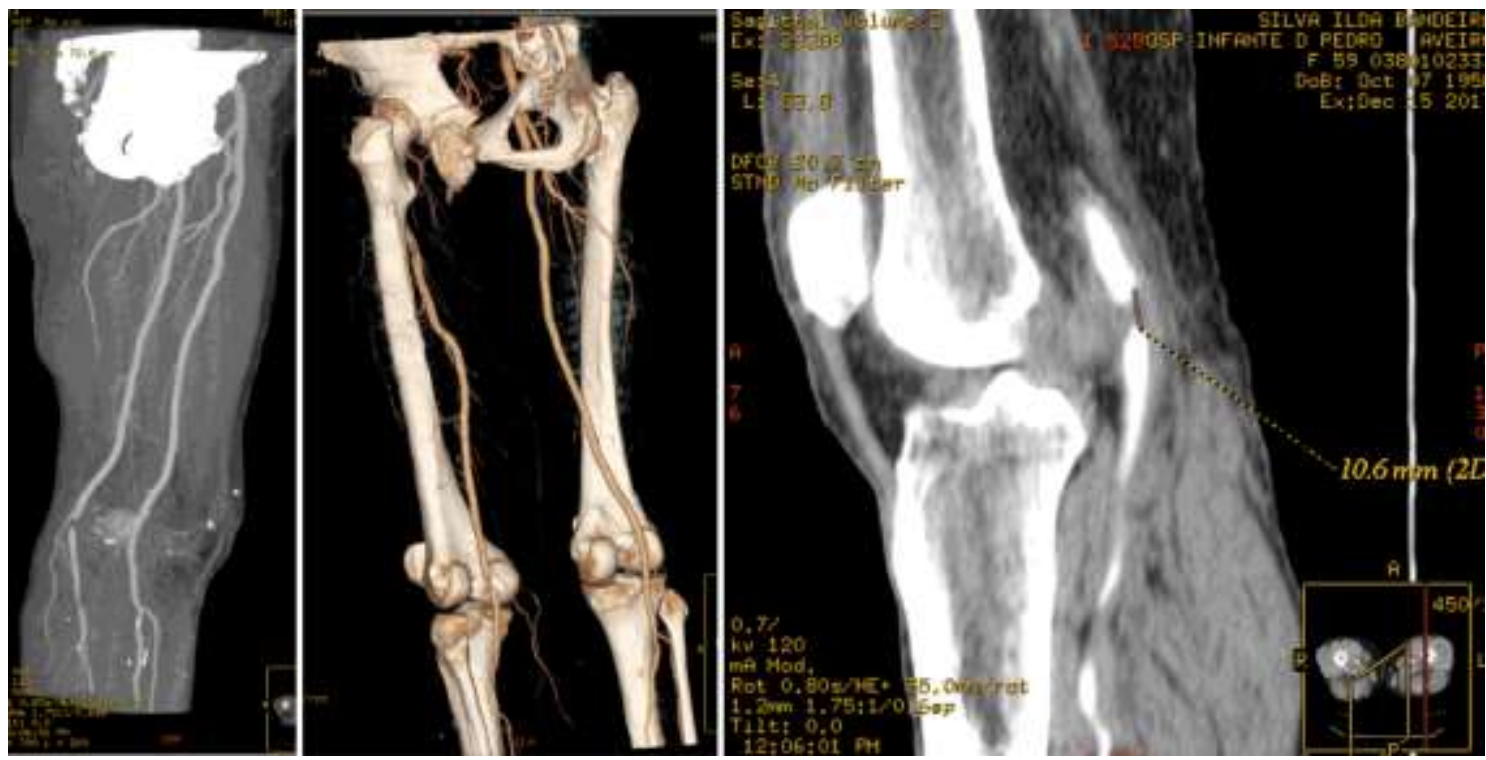

Figure 2: AngioTC with the popliteal artery injury

The patient was transferred to a hospital with Vascular Surgery and Department and underwent infra-articular femoro-popliteal bypass with an inverted homolateral great saphenous vein. Immobilization with the plaster splint was applied.

After a period of surveillance at the Orthopedics service at the area of residence Hospital, the patient was discharged for a follow-up consultation, with a long leg plaster cast.

Ten weeks after the injury, the cast was removed and she underwent progressive loading on the limb, and started physical rehabilitation (Figure 3). Distal pulses were always present and symmetrical. An instability in the varus stress test was observed, but it did not manifest itself while walking.
At 3 months, she had an occasional sense of instability in her left knee and, on physical examination, a posterior fall of the tibia with a positive posterior drawer, but with normal varus stress, was identified. A MRI was performed, which revealed a non-definition of the proximal third of the posterior cruciate ligament and marked diffuse thickening of the fibers of the anterior cruciate ligament. At 6 months of follow-up, she had an occasional mechanical left knee pain, associated with a feeling of knee instability that did not limit her activities of daily living. She walked without gait support and had knee mobility of 0-120 degrees. Consequently, she declined any surgery to correct the instability. 


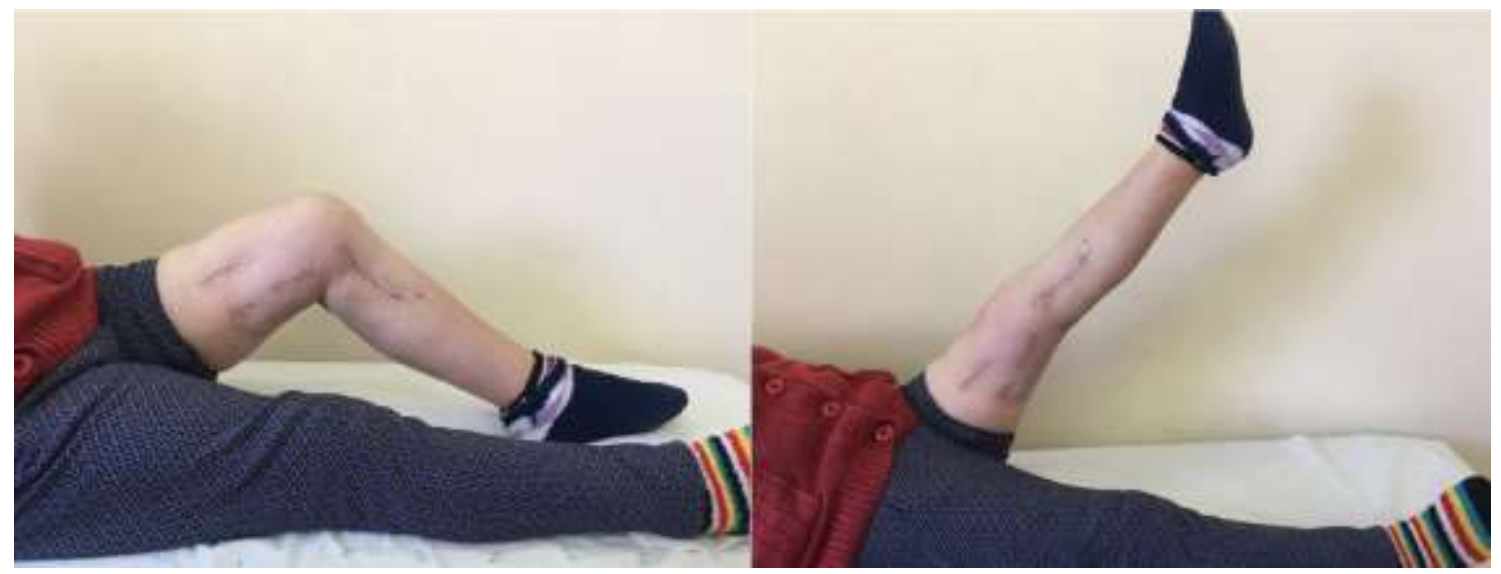

Figure 3: Mobility of the knee before rehabilition

\section{DISCUSSION}

Knee dislocation with associated neurovascular injury is a serious and potentially a limb-threatening problem. $[1,11]$ Early diagnosis is extremely important, because if the vascular injury is not repaired within 8 hours of ischemia, the amputation rate is $86 \%$. Hense, the clinician must be sensitive to detect an absence or asymmetry of the pulses at the distal level as well as a decrease or asymmetry in the temperature of the leg and foot compared to the contralateral limb. These findings should then be confirmed by imaging with echo-doppler, angiography or CT angiography. [12]

Ocasionally, knee dislocations are followed by severe leg edema, which can lead to a compartment syndrome. This complication requires a fasciotomy of the 4 compartments, without hesitation. In this specific case the procedure was not necessary, and the patient did not show any signs of muscle fibrosis during follow-up. [12, 13]

Balkfors et al state that late knee symptoms after extensive ligament injury are independent of the nature of the treatment. $[14,15]$ In this case, the knee

1. Howells NR, Brunton LR, Robinson J, Porteus AJ, Eldridge JD, Murray JR. Acute knee dislocation: an evidence based approach to the management of the multiligament injured knee. Injury. 2011; 42:1198-1204.

2. Seroyer ST, Musahl V, Harner CD. Management of the acute knee dislocation: the Pitts burgh experience. Injury. 2008; 39:710- 718 .

3. Henrichs A. A review of knee dislocations. J Athl Train. 2004; 39:365-369.

4. Merritt AL, Wahl C. Initial assessment of the acute and chronic multiple-ligament injured (dislocated) knee. Sports Med Arthrosc. 2011; 19:93-103.

5. Johnson ME, Foster L, DeLee JC. Neurologic and vascular injuries associated with knee ligament injuries. Am J Sports Med. 2008; 36:2448-2462.

6. Fanelli GC, Orcutt DR, Edson CJ. The multiple ligament injured knee: evaluation, treatment, and results. Arthroscopy. 2005; 21: 471-486.

7. Darcy G, Edwards E, Hau R. Epidemiology and outcomes of traumatic knee dislocations: Isolated vs multi- trauma injuries. Injury. 2018 Jun;49(6):1183-1187.

8. Arnold C, Fayos Z, Bruner D, Arnold D, Gupta N, Nusbaum J. Managing dislocations of the hip, knee, and ankle in the emergency department [digest]. Emerg Med Pract. 2017 Dec 20;19(12 Suppl Points \& Pearls):1-2. had a slight instability without affecting the patient's daily activities, thus any corrective surgical intervention was required.

The authors present this way a case of a patient with a knee dislocation associated with a vascular injury that was treated conservatively for the orthopaedic lesion resulting in minor instability and without other major complications.

\section{CONCLUSION}

Knee dislocation associated with a popliteal artery lesion is a rare trauma requiring immediate management by an orthopaedic surgeon and a vascular surgeon, acting in concert. First should be treated the vascular limb threatening and secondary ligament repair procedures will be discussed on a case-by-case basis, depending on age and patient demandings, not forgetting that a conservative treatment is always an option.

\section{REFERENCES}

9. Jones, R: E., Smith, E. C. \& Bone, G. E. (1979) Vascular and orthopedic complications of knee dislocation. Surg. Gynecol. Obstet. 149, 554-558.

10. Meyers, M.H., Moore, T. M. \& Harvey, J. P. (1975) Traumatic dislocation of the knee joint. J. Bone Joint Surg. 57-A,430433.

11. Nicandri GT, Chamberlain AM, Wahl CJ. Practical management of knee dislocations: a selective angiography protocol to detect limb- -threatening vascular injuries. Clin J Sport Med. 2009; 19: 125-129.

12. Patterson BM, Agel J, Swiontkowski MF, Mackenzie EJ, Bosse MJ, LEAP Study Group. Knee dislocations with vascular injury: outcomes in the Lower Extremity Assessment Project (LEAP) study. J Trauma. 2007; 63:855858.

13. Stannard JP, Sheils TM, Lopez-Ben RR, McGwin G, Robinson JT, Volgas DA. Vascular injuries in knee dislocations: the role of physical examination in determining the need for angiography. J Bone Joint Surg Am. 2004; 86:910-915.

14. Wascher DC, Dvimak PC, DeCoster TA. Knee dislocation: initial assessment and implications for treatment. J Orthop Trauma. 1997; 11:525-529.

15. Balkfors, B. (1982) The course of knee-ligament injuries. Acta Orthop. Scand. Suppl. 198. 
(cC) ()

This work is licensed under Creative Commons Attribution 4.0 License

To Submit Your Article Click Here: Submit Manuscript

DOI:10.31579/2694-0248/014
Ready to submit your research? Choose Auctores and benefit from:

* fast, convenient online submission

* rigorous peer review by experienced research in your field

* rapid publication on acceptance

* authors retain copyrights

* unique DOI for all articles

* immediate, unrestricted online access

At Auctores, research is always in progress.

Learn more https://www.auctoresonline.org/journals/clinical-orthopaedicsand-trauma-care 